\title{
Assessing Bayesian Racism Scale: Measuring Endorsement of Racial Stereotypes
}

\author{
Stacey Diane Arañez Litam ${ }^{1}$ D $\cdot$ Richard S. Balkin² ${ }^{2}$
}

Accepted: 14 April 2021 / Published online: 24 April 2021

(C) The Author(s), under exclusive licence to Springer Science+Business Media, LLC, part of Springer Nature 2021

\begin{abstract}
Bayesian racism is the belief that it is rational to discriminate against people based on existing racial stereotypes. The presence of Bayesian racism is strongly associated with negative feelings about minoritized groups and the desire to maintain racially inequitable social hierarchies. A confirmatory factor analysis on the Bayesian Racism Scale (BRS) yielded a unidimensional measure for assessing prejudicial attitudes that endorse stereotypes based on racial and ethnic groups. Findings from the study have important implications for multicultural and social justice research.
\end{abstract}

Keywords Racism - Bayesian Racism Scale · Prejudice · Contemporary racism • Counselling research

\section{Introduction}

The counselling profession has demonstrated a strong commitment to enhancing the abilities of counsellors to work effectively with diverse clients since multiculturalism was identified as the "fourth force" of counselling and psychology (Pedersen, 1988, 1989, 1990). Regardless of client population, geographic location, or workplace setting, understanding client values, and how religious identities may influence social justice worldviews and endorsement of religious racism, are foundational goals for professional counsellors. As evidenced by these important professional values, research related to multiculturalism, diversity, acceptance, and tolerance represent a longstanding area of critical research (Gonzalez-Voller et al., 2020; Hays, 2020).

Stacey Diane Arañez Litam

s.litam@csuohio.edu

1 Counseling, Administration, Supervision, and Adult Learning Department, Cleveland State University, $\mathrm{OH}$, Cleveland, USA

2 Department of Leadership \& Counselor Education, The University of Mississippi, MS, Oxford, USA 


\section{Racial Bias and Microaggressions}

Although overt assertions that espouse monocultural ethnocentric values are deemed unacceptable in the United States (Morrison \& Kiss, 2017), racism continues to occur in both overt and subtle forms. For example, endorsement of White supremist notions and racist rhetoric have substantially increased following Trump's election (Konrad, 2018; Sanchez, 2018) and during the COVID-19 pandemic (Anandavalli et al., 2020; Litam, 2020; Litam \& Oh, 2020; Oh et al., in press). Whereas overt forms of racism may be more likely to occur when racist acts go unpunished (Sullivan et al., 2016) or when individuals believe their acts are anonymized (Sue et al., 2016), the extant body of research has established how subtle forms of racism may be embedded in rationalizable attitudes masked within discourse about fairness and deservingness (Bank, 2016; Crandall \& Eschelman, 2003; Morrison \& Kiss, 2017).

Racial bias may be more likely to occur when situations can be intellectualized as occurring for nonracist reasons (Arkes \& Tetlock, 2004; Khan \& Lambert, 2001; Malkin, 2004; Morrison \& Kiss, 2017), or when prejudice can be justified as the result of rational probabilities (Uhlmann \& Brescoll, 2011). Attempts to intellectualize racial bias and deny personal responsibility may be evidenced when White police officers shoot unarmed Black suspects and rationalize their motives as selfdefense while overlooking the presence of implicit racial bias. The importance of illuminating the underlying mechanisms that contribute to racial stereotyping is of paramount importance for professional counsellors who may find themselves working with clients who endorse racial biases, such as police officers and/or conservative religious client (Litam et al., in press).

Microaggressions are the everyday slights, insults, invalidations, and offensive behaviors experienced by people of color through interpersonal, verbal, and nonverbal forms of communication (Sue \& Sue, 2016). The extant body of research has examined how counsellor microaggressions impact client wellbeing and the therapeutic process (Hook et al., 2016; Owen et al., 2014). Counsellors who engaged in racial microaggressions were associated with lower levels of perceived competence and influenced lower levels of well-being among clients (Owen et al., 2011, 2014). Hook and colleagues (2016) identified denial of stereotypes or bias about cultural issues as the most frequently reported racial microaggression among a sample of racial/ethnic minority participants $(n=2,212)$. Professional counsellors are therefore called to critically consider whether they themselves hold internalized racial biases about clients of color and are encouraged to take ownership when racial microaggressions occur.

\section{Racial Bias and Religious Racism}

Religious racism refers to the paradox wherein religious in-group members endorse racial out-group prejudice (Burris \& Jackson, 2000), and has been well established in the extant body of research (Allport, 1950; Hall et al., 2010; Singh \& Crowden, 
2011). Hall and colleagues (2010) posit that individuals who strongly adhere to religious identities tend to be ethnocentric, which may uniquely position them in ways that promote racial biases and minimize the importance of alternative perspectives. For example, researchers have hypothesized that though religious beliefs and practices may center around egalitarian and humanitarian principles, Christian ideologies may also endorse notions of social conventionalism, authoritarian belief systems, and an unwavering acceptance of the social order and status quo in ways that contribute to religious racism (Hall et al., 2010; Roccas, 2005; Spangenberg, 2019). Additional values commonly espoused by conservative religious communities include endorsement of the Protestant work ethic and respect for tradition, both of which have been linked to religious racism (Hall et al., 2010; Tarman \& Sears, 2005), In a meta-analysis of 55 studies using a total of 22,075 participants, predominantly White Christians in the U.S., greater religious identification, higher levels of extrinsic religiosity, and greater religious fundamentalism were all positively associated with racism (Hall et al., 2010). According to Hall and colleagues (2010), these findings suggest, "motives to be religious also are a motivator of racism" (p. 135). Given the greater likelihood of religious racism and racial bias that may be present among Conservative Christians, studies that seek to understand the cognitive processes of this unique population are critical to develop research studies that investigate the effects of endorsing racist attitudes, such as Bayesian racism.

\section{Bayesian Racism}

Using statistical probabilities to inform decisions about vague, unknown predicaments exists across the fields of statistics and the philosophy of science (Bernardo \& Smith, 1994; Savage, 1954). For instance, Bayesian inference uses an estimate of the degree of belief in a hypothesis before evidence is known, to calculate an estimate of what will occur (Gelman \& Shalizi, 2013). Engaging in Bayesian process occurs when people want to infer, based on what they know, to directly solve an equation. Although Bayesian analysis represents a direct strategy to solve statistical problems, limitations related to mathematical difficulties, additional assumptions, and uncertainties exist (Eddy, 2004). When statisticians and mathematicians infer outcomes based on what they believe to know, they inadvertently lack an objective method of induction. Challenges arise when what is believed to be known is actually false.

The Bayesian concept of applying anticipated knows to inform decisions has not yet been established within the counselling field. A measure of Bayesian racism may represent a helpful measure for multicultural competence within the counselling profession (Litam et al., in press). Bayesian racism is the belief that it is rational to discriminate against people based on existing racial stereotypes (Uhlmann \& Brescoll, 2011; Uhlmann et al., 2010), and occurs when people assert to using known information about a particular racial or ethnic group to inform their decision making. The presence of Bayesian racism is strongly associated with negative feelings about minoritized groups and the desire to maintain racially inequitable social hierarchies (Uhlmann et al., 2010). Although individuals who endorse Bayesian racism may claim that their assertions are evidenced by desires to leverage objective 
thought Bayesian racism was found to negatively correlate with indices of rational thinking (Uhlmann et al., 2010). Thus, people who assert they were endorsing racial stereotypes for accuracy purposes were actually less likely to do so. Individuals who endorse Bayesian racism were also more likely to believe that race differences in violent crimes were due to biological factors (Uhlmann et al., 2010). These perspectives may create opportunities for ongoing racial discrimination and the endorsement of harmful race-based narratives that can perpetuate cycles of aggression towards minoritized groups. Professional counsellors who endorse Bayesian racism risk engaging in racial stereotypes that lead to poorer treatment outcomes and interfere with ethical and efficacious service delivery. For example, counsellors who unknowingly endorse Bayesian racism may be more likely to attribute client problems to their race and/or ethnicity rather than recognize how minoritized clients often navigate challenges at the intersection of race, ethnicity, class, gender, and other identities.

\section{The Bayesian Racism Scale}

The Bayesian Racism scale (BRS; Uhlmann et al., 2010) measures the belief that it is rational to discriminate against individuals based on racial stereotypes. Uhlmann and colleagues (2010) derived item content from theories associated with rational stereotyping and racism. Specifically, three underlying antecedents were identified: (a) threatened egotism (e.g., Fein et al, 2003), in which a culture of power tends to discriminate against those to whom they view as threatening to their ego; (b) system justifying motivations (e.g., Judd \& Park, 1993), in which a group seeks to elevate their own status and lower the status of outside groups; and (c) accuracy motives (e.g., Fiske, 2001), which occurs when people endorse stereotyping to facilitate their worldviews (Uhlmann et al., 2010).

Although the scores on the BRS were reported to form a reliable measure $(\alpha=0.74)$, a factor analysis (neither exploratory nor confirmatory) to address the unidimensional structure of the scale was not conducted. Understanding the motives that influence stereotype-based discrimination against marginalized groups are important to begin combatting forms of racism and White supremacy couched under the guise of epistemic rational judgment. The purpose of the present study was to validate the psychometric properties of the BRS. This study served as a secondary analysis from a previous study related to the relationship of worry, Bayesian racism, and belief in a just world among White Evangelical Christians (Litam et al., in press).

\section{Rationale for the Study}

According to Hays (2020), researchers who engage in multicultural and social justice research employ culturally appropriate research designs, address aspects of social privilege and power within the counselling relationship and use research as a means of advocacy. Advocacy in research seeks to empower clients and address 
existing barriers that contribute to inequitable mental health and services and lead to poorer therapeutic outcomes (Chapman \& Schwartz, 2012; Kozan \& Blustein, 2018; Ramirez Stege et al., 2017; Shin et al., 2016). Now more than ever, the importance for counsellors to identify and challenge underlying attitudes and beliefs that may contribute to the endorsement of racial stereotypes and White supremacy cannot be understated. Focusing on the differences of minoritized groups may result in perpetuating stereotype endorsement among clients with diverse identities, rather than increasing their skills to work with each client through an individualized lens. Counsellors must therefore recognize how privileged and oppressed identities uniquely interplay within the therapeutic setting (Ratts et al., 2016). Because counsellors are in a position of power, notions and attitudes about their clients have implications for diagnoses, case conceptualization, and treatment planning (Kottler \& Balkin, 2017). Validating assessments that measure tendencies toward endorsing race-based biases are critical to further propel counselling research that addresses racialized oppression and discrimination.

\section{Method}

\section{Participant Characteristics}

In this study, 211 adults initiated participation with 195 participants completing the survey for a completion rate of $92.4 \%$. With respect to demographic characteristics of the participants, 87 (44.6\%) were male and 108 (55.4\%) were female; age ranged from 18 to 88 with mean of $49.43(\mathrm{SD}=15.36)$; $174(89.2 \%)$ were non-Hispanic White, 13 (6.7\%) were Hispanic, Chicano or Latino, 4 (2.1\%) were African American, $2(1 \%)$ were biracial or multiracial, $1(0.5 \%)$ was Asian or Asian American, and $1(0.5 \%)$ was Native American or Alaskan Native; 120 (61.5\%) identified as Evangelical Christian or Protestant; 28 (14.4\%) identified as Mormon or The Church of Jesus Christ of Latter Day Saints, 37 (19\%) identified as another Christian faith, and $10(5.1 \%)$ identified as Agnostic.

\section{Procedures and Data Collection}

The study was approved by the researchers' Institutional Review Board (IRB) prior to beginning the study. Participants were recruited from a convenience sample of national Evangelical Christian and Mormon/The Church of Jesus Christ of Latter Day Saints congregations across the United States known to the authors. Church leaders utilized social media and emails to encourage participation. Participants were informed that responses were anonymous, there was no reward for participation, completion of the measure indicated consent, and participants could discontinue participation at any time with no consequence.

Data were collected over a two-week period using Qualtrics $(n=178,91.3 \%)$ and in-person administrations $(n=17,8.7 \%)$. Data were analyzed using JASP (v. 0.12.1). Participants completed a demographics and background form followed by three 
measures, including the BRS. As this study represents a secondary analysis, only scores from the BRS and demographic information were used.

\section{Sample Size, Power, and Precision}

Recommended sample size for CFA varies (Jackson et al., 2009). Schreiber et al. (2006) recommended 10 participants per parameter as a common consensus. In this CFA, six regressions and one covariance were specified, yielding 13 parameters. Consequently, 195 participants yielded a ratio of 15 participants per 1 parameter estimate.

\section{Measures}

The Bayesian Racism Scale (BRS; Uhlmann et al., 2010) consists of 6 items that measure adherence to Bayesian racism, the belief that it is rational to discriminate against individuals based on racial stereotypes (Uhlmann et al., 2010). Examples of statements include "Law enforcement officers should pay particular attention to those social groups more heavily involved in crime, even if it means focusing on members of particular ethnic groups", and "When the only thing you know about someone is their race, it makes sense to use your knowledge of their racial group to form an impression of them." Each item is rated on a seven-point Likert-type scale consisting of the following indicators: 1 "Strongly disagree," 2 "Disagree," 3 "Somewhat disagree," 4 "Neither agree nor disagree," 5 "Somewhat agree," 6 "Agree," and 7 "Strongly agree." Two items are reverse scored (see Table 1). Whereas a total score of 24 may be indicative of indifference toward Bayesian racism, higher scores may indicate stronger adherence to Bayesian racism. Development of the Bayesian Racism Scale consisted of 109 participants in which correlations with existing measures of prejudice and rational thinking were described and internal consistency of the scores was evaluated. The Bayesian Racism scale was positively correlated with Social Dominance Orientation-the endorsement that social group hierarchy is desirable $(r=0.55)$ and the belief that race differences in violent crime are due to biological factors ( $r=0.53$; Sidanius \& Pratto, 1999; Uhlmann et al., 2010). The scores represent sufficient evidence of internal consistency $(\alpha=0.74)$. In this study, internal consistency estimates for scores on the Bayesian Racism scale yielded a Cronbach's alpha of 0.80 (95\% CI [0.75, 0.84]).

\section{Data Diagnostics}

A primary assumption of CFA is multivariate normality (Jackson et al., 2009). In the absence of a robust process for evaluating multivariate normality in JASP or SPSS, univariate normality for each of the six items were assessed. Distributions for all items were positively skewed, with $56.4 \%$ to $81 \%$ or the participants endorsing tendencies contrary to racist beliefs (e.g., 1 [strongly disagree] or 2 [disagree]) to 


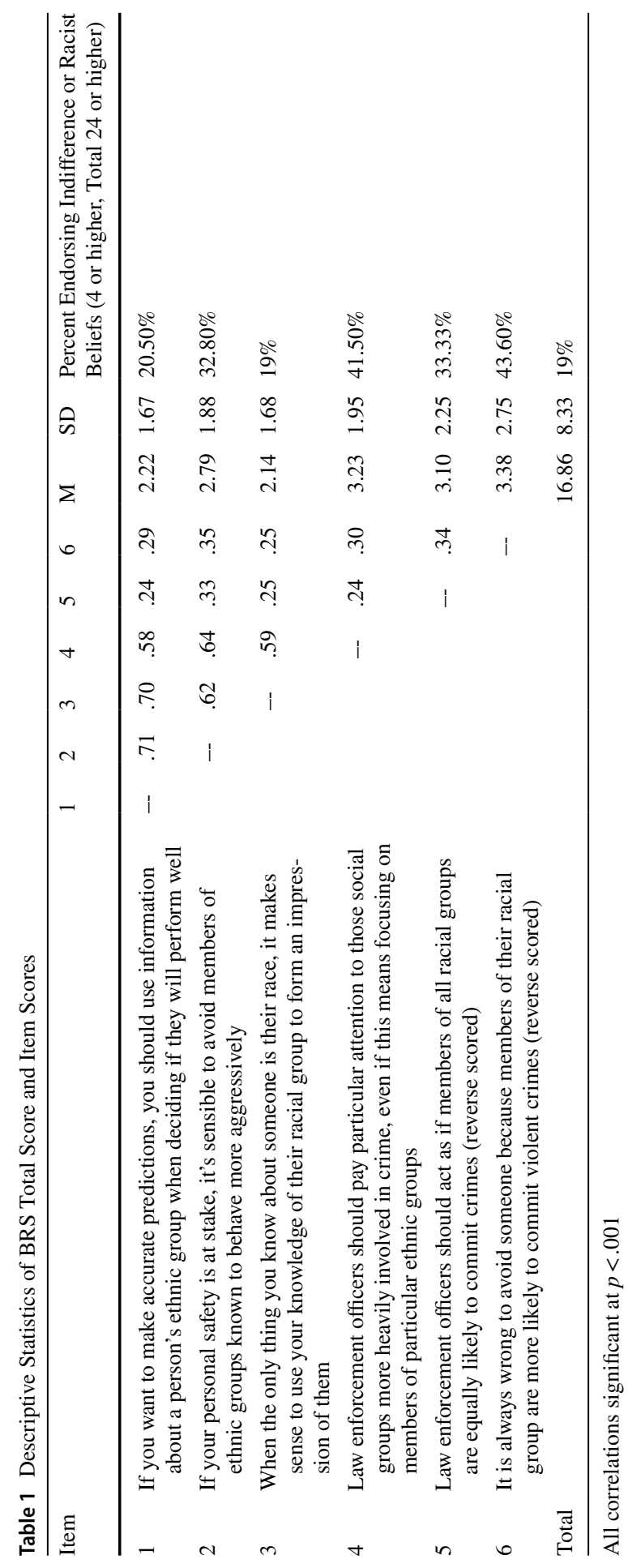


each of the items. No multivariate outliers were identified. A forced response format was used in Qualtrics to eliminate problems of missing data.

\section{Analytic Strategy}

Preliminary analyses consisted of descriptive statistics for items on the BRS. For the primary analysis, a confirmatory factor analysis (CFA) was conducted using JASP version 0.12. Maximum Likelihood (ML) is the most common procedure for CFA and is typically robust to minor violations of nonnormality (Jackson et al., 2009). However, as some of the items were highly skewed, Li (2016) recommended use of weighted least squares (WLSMV), as this method makes no distributional assumptions of the data. Hence, findings from both methods were reported.

\section{Results}

\section{Preliminary Analysis}

The BRS was developed as a six-item unidimensional measure that uses a 7-point Likert-type format resulting in scores that range from 6 to 42 (Uhlmann et al., 2010). For the sample of 195 participants in this study, scores were positively skewed $(\mathrm{M}=16.86, \mathrm{SD}=8.33)$. Based on the positively skewed results of the current study, $60 \%(n=117)$ of participants reported total scores of 18 or less on the BRS, indicative of slight to strong feelings of disagreement with racist beliefs. Total scores of 24 or higher were more clearly associated with indifference to strong feelings of endorsement of racist beliefs $(19 \%, \mathrm{n}=37)$. Each of the six items were also positively skewed with $19 \%(n=37)$ to $43.6 \%(n=85)$ of the participants endorsing indifference to or presence of racist beliefs on each item (see Table 1).

\section{Primary Analysis}

A CFA was conducted to evaluate the unidimensional model of the BRS as hypothesized by Uhlmann et al. (2010) using ML parameter estimation. The observed model was statistically significant different from the hypothesized model, $\chi^{2}(9)=26.53$, $p=0.002$. Evidence of a marginal fit was indicated by the CFI $=0.96, \mathrm{TLI}=0.936$, and RMSEA $=0.100$ (95\% CI [0.057, 0.145]). Modification indices indicated the model may be improved through the correlation of error variances for items five and six, which both evaluated perceptions of law enforcement with respect to racism. Hence, a theoretical commonality between these items was evident. Upon correlating the error variances, the observed model was a good fit to the hypothesized model, $\chi^{2}(8)=14.148, p=0.078$ (see Table 2 and Fig. 1). Further evidence of a good fit was indicated by the CFI $=0.986, \mathrm{TLI}=0.975$, and $\mathrm{RMSEA}=0.063(95 \%$ CI $[0,0.115])$. 
Table 2 Standardized and Unstandardized Coefficients for CFA

\begin{tabular}{|c|c|c|c|c|c|c|c|}
\hline \multicolumn{8}{|l|}{ ML } \\
\hline \multirow[b]{2}{*}{ Indicator } & \multirow[b]{2}{*}{$\beta$} & \multirow[b]{2}{*}{ B } & \multirow[b]{2}{*}{ SE } & \multirow[b]{2}{*}{ z-value } & \multirow[b]{2}{*}{$p$} & \multicolumn{2}{|c|}{$\begin{array}{l}95 \% \text { Confidence } \\
\text { Interval }\end{array}$} \\
\hline & & & & & & Lower & Upper \\
\hline B1 & 0.84 & 1.41 & 0.10 & 13.92 & $<.001$ & 1.21 & 1.61 \\
\hline B2 & 0.84 & 1.57 & 0.11 & 13.77 & $<.001$ & 1.35 & 1.79 \\
\hline B3 & 0.79 & 1.32 & 0.11 & 12.55 & $<.001$ & 1.11 & 1.52 \\
\hline B4 & 0.73 & 1.43 & 0.13 & 11.36 & $<.001$ & 1.18 & 1.67 \\
\hline B5 & 0.33 & 0.74 & 0.17 & 4.48 & $<.001$ & 0.42 & 1.07 \\
\hline B6 & 0.37 & 0.83 & 0.16 & 5.05 & $<.001$ & 0.51 & 1.15 \\
\hline \multicolumn{8}{|l|}{ WLSMV } \\
\hline B1 & 0.86 & 1.47 & 0.11 & 12.89 & $<.001$ & 1.24 & 1.69 \\
\hline B2 & 0.88 & 1.60 & 0.09 & 18.63 & $<.001$ & 1.43 & 1.76 \\
\hline B3 & 0.81 & 1.35 & 0.13 & 10.42 & $<.001$ & 1.10 & 1.60 \\
\hline B4 & 0.74 & 1.43 & 0.09 & 16.52 & $<.001$ & 1.26 & 1.60 \\
\hline B5 & 0.34 & 0.76 & 0.16 & 4.88 & $<.001$ & 0.46 & 1.07 \\
\hline B6 & 0.34 & 0.76 & 0.15 & 5.15 & $<.001$ & 0.47 & 1.05 \\
\hline
\end{tabular}

Given the nature of highly skewed distributions, the corrected model was tested to the hypothesized model using WLSMV (Li, 2016). The observed model was a good fit to the hypothesized model, $\chi^{2}(8)=12.603, p=0.126$ (see Table 2). Further evidence of a good fit was indicated by the CFI $=0.957, \mathrm{TLI}=0.919$, and RMSEA $=0.054$ (95\% CI [0, 0.109]).

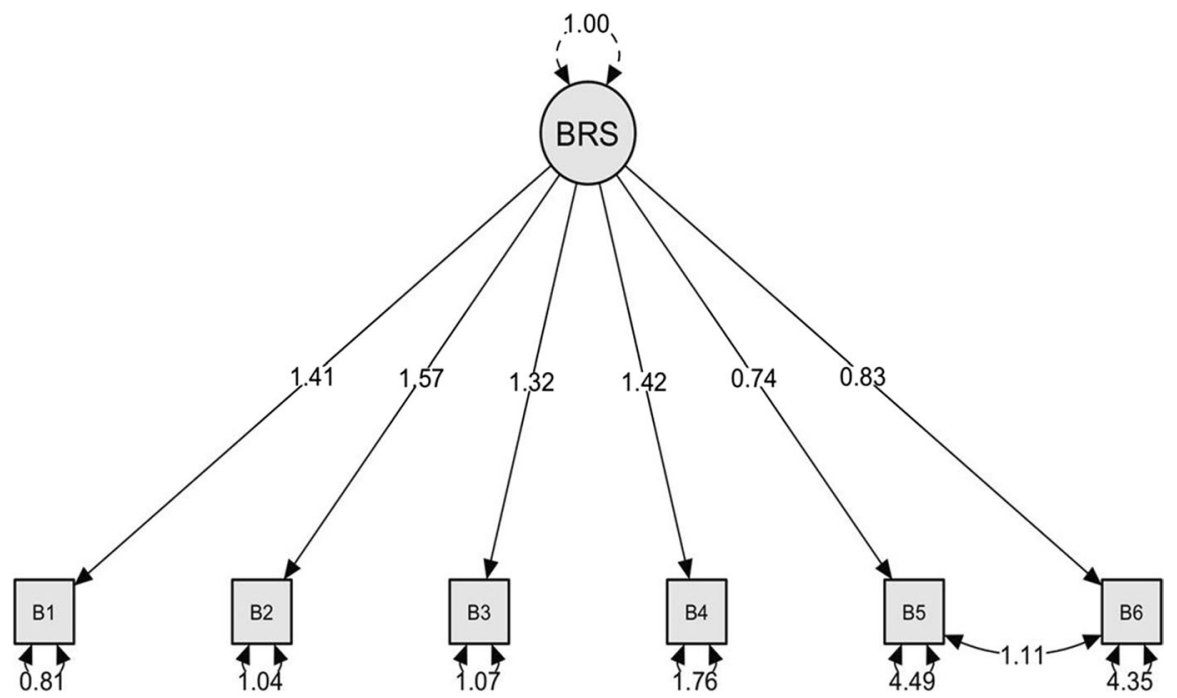

Fig. 1 Corrected model with maximum likelihood 


\section{Discussion and Implications}

The importance of engaging in social justice and multicultural research in the counselling profession has been established (Hays, 2020). Although counselling researchers espouse the importance of engaging in racism-focused research, an instrument that acknowledges how individuals may believe that it is rational to discriminate against others based on racial stereotypes has not yet been well incorporated in the counselling literature (Litam et al., in press). Counselling researchers may therefore use the BRS to expound upon new understandings of racism and to supplement the existing body of work.

Whereas overt forms of racism are easier to recognize, subtle, covert forms of racism require special consideration and may be identified through the use of the BRS. The BRS may therefore be operationalized as an advocacy, professional development, self-reflection, and/or assessment tool that empowers professional counsellors and counselling researchers to examine the presence of a unique aspect of racism and racial bias in research, in clients, and within ourselves. Based on the results of our study, the BRS may represent a social justice-oriented instrument that can help professional counsellors and counselling researchers measure specific forms of racial biases that are perpetuated in socially overlooked and complex ways and remain outside of conscious awareness (Helms, 2015; Sue, 2005; Sue \& Sue, 2016).

Preliminary work on the BRS (Uhlmann et al., 2010) provided some evidence based on test content and relations to other variables (AERA et al., 2014), as well as estimates of reliability for the initial development of the scale. In this study, a CFA indicated evidence of a unidimensional measure. Our estimate of internal consistency appeared stronger for the reliability of the scores on the BRS than Uhlmann et al. The BRS appears to have strong evidence of validity to measure Bayesian racism with accuracy and consistency.

The majority of the participants in this study did not endorse racist ideology, but on four of the six items, response rates endorsing racist ideology ranged from $32.80 \%$ to $43.60 \%$ of the participants. Based on these results, the BRS may promote honesty in responses across a construct, endorsement of Bayesian racism, that has been previously difficult to measure without accounting for social desirability. Part of the challenge in measuring racism lies in the pressure to produce socially desirable responses coupled with the unconscious bias of respondents (Blanton \& Jaccard, 2017). Yet, the nature of the BRS items may be perceived as less threatening, and therefore engender more honest responses. For example, support for law enforcement officers is often associated with strong, conservative values (Morgan et al., 2010). Therefore, responses to items related to law enforcement may have been perceived as a show of support as opposed to an endorsement of racial bias and Bayesian racism.

Consistent with the call to incorporate professional counselling values of multiculturalism, diversity, and acceptance into research (Gonzalez-Voller et al., 2020; Hays, 2020), the BRS may be an effective measure to evaluate endorsement of racial stereotypes that are not perceived as racist by the respondent. In this study, the endorsement of Bayesian racism occurred without the use of a social desirability measure, providing a more streamlined process to evaluate racist ideology without the confounding effects of accounting for social desirability. Although it is possible 
that utilization of the BRS still produces an underestimate of racial bias, the item level statistics (i.e., scores of 4 or higher on an item) point to a conceivable number of participants who endorse racist ideology.

Given the ethical obligations for counsellors to demonstrate the knowledge, skills, and awareness necessary to work with diverse clients (American Counseling Association, 2014), counsellors must be prepared to support clients who endorse racial biases outside of their conscious awareness. Thus, professional counsellors may consider including the BRS measure as part of a client intake packet or disseminate the items in-person. Counsellors must recognize how clients that endorse aspects of Bayesian racism may attribute their racial stereotypes to notions of fairness, rational decision making, or deservingness (Banks, 2016; Uhlmann \& Brescoll, 2011; Uhlmann et al., 2010). When clients who report high levels of religious identification may struggle to alleviate feelings of shame regarding the internalization of religious racism, professional counsellors may use the BRS as a strategy to provide psychoeducation. For example, counsellors could briefly discuss how conservative religious beliefs and practices could have socialized clients to internalize specific values (i.e., Protestant work ethic, authoritarian belief systems, and respect for tradition) and acceptance of social order in ways that may have contributed to the presence of religious racism (Hall et al., 2010; Roccas, 2005; Spangenberg, 2019). Using the BRS in this way may support Conservative religious clients who experience dissonance between the values held and attitudes endorsed. Empathic interventions, such as reality checks, psychoeducation, and gentle confrontation may therefore be helpful strategies to begin untangling clients' racial biases in ways that allow them to form more culturally sensitive and accurate worldviews. Counsellors can additionally empower clients to unpack socialized messages internalized from early caregivers, family of origin, media, or community members. For example, when clients state, "Black men are more dangerous than White men", counsellors can gently confront clients, identify the etiology of client beliefs, and instill accurate information by simply asking, "Who told you that this was true?".

The BRS may also be implemented in ways that empower professional counsellors to reflect on whether they themselves endorse aspects of Bayesian racism and racial bias. Engaging in ongoing self-reflection and raising ones' critical consciousness continue to represent important strategies for counsellors who work toward cultural competence. The extant body of research has illuminated how counsellors who engaged in racial microaggressions influenced lower well-being among clients (Owen et al., 2011, 2014). Furthermore, denying endorsement of racial stereotypes was identified as the most frequently occurring racial microaggression (Hook et al., 2016). Professional counsellors may therefore consider implementing the BRS within school, community, agency, private practice, and other settings to promote self-evaluation and enhance professional development. Engaging the BRS in this unique way may help professional counsellors uncover the potential presence of underlying racial biases and provide opportunities for increases cultural competency.

\section{Limitations and Suggestions for Further Research}

As the sensitivity of the BRS has not been evaluated, the extent to which the BRS either underestimates or overestimates racist ideology requires further study. The 
data collected in the sample was also positively skewed. Nevertheless, the data from this study indicate some promise in the use of a brief instrument to assess the prevalence of a singular construct of racist ideology-Bayesian racism. Future research is necessary to evaluate the utility of the BRS with more varied populations, including with counsellor trainees and professional counsellors. Future studies may also examine whether the BRS produces similar finding across diverse populations and cultures. Translating and validating the BRS into other languages may represent important strategies to identify the presence of anti-Black notions and Bayesian racism across cultures. Given the superior ability of the BRS to measure endorsement of Bayesian racism, researchers are called to use the measure in ways that identify individuals who endorse racist ideologies and may promote the MSJCC aspirational competencies of attitudes and beliefs. Once identified, participants may be encouraged to complete anti-racism training and challenge their internalized bias towards racial and ethnic groups. Using the BRS with individuals in law enforcement represents another important area of future study. Researchers may also use the BRS with students enrolled in police academies and criminal justice programs to illuminate attitudes that may be harmful when serving communities of color. As students enrolled in these fields report desires to pursue careers in law enforcement or within criminal justice systems (Jackson \& Henderson, 2019), the BRS may be used as a screening measure that identifies candidates in need of anti-racism training. Facilitating early anti-racism interventions with individuals imbued with power to oppress communities of color are invaluable.

\section{Conclusion}

Measuring endorsement of racial stereotypes represents a valuable contribution to the extant body of multicultural and social justice counselling research. Identifying the propensity to endorse racial stereotypes and Bayesian racism empowers individuals to challenge underlying biases in ways that embolden counsellors to promote client wellbeing and mitigate the effects of discrimination towards communities of color. The results of a confirmatory factor analysis on the BRS yielded a unidimensional measure that may represent a valuable tool for assessing a specific form of contemporary racism that may not be perceived as racist by the respondent. Researchers are called to use the BRS to engage in studies aimed at addressing the social injustice perpetuated by oppressive systems in power that create barriers to client overall wellbeing.

\section{References}

Allport, G. W. (1950). The individual and his religion. Macmillan.

American Counseling Association. (2014). ACA Code of Ethics. https://www.counseling.org/docs/defau lt-source/default-document-library/2014-code-of-ethics-finaladdress.pdf?sfvrsn=96b532c_2 
American Educational Research Association, American Psychological Association, National Council on Measurement in Education, Joint Committee on Standards for Educational and Psychological Testing (U.S.). (2014). Standards for educational and psychological testing. AERA.

Anandavalli, S., Harrichand, J. S., \& Litam, S. D. A. (2020). Counseling international students in times of uncertainty: A critical feminist and bioecological approach. The Professional Counselor, 10(3), 365-375. https://doi.org/10.15241/sa.10.3.365

Arkes, H. R., \& Tetlock, P. E. (2004). Attributions of implicit prejudice, or -Would Jesse Jackson fail the Implicit Association Test? Psychological Inquiry, 15, 257-279

Bank, J. (2016). Mr. Winterkorn's pay: a typology of justification patterns of income inequality. Social Justice Research, 29(2), 228-252

Bernardo, J. M., \& Smith, A. F. M. (1994). Bayesian theory. Wiley.

Blanton, H., \& Jaccard, J. (2017). You can't assess the forest if you can't assess the trees: Psychometric challenges to measuring implicit bias in crowds. Psychological Inquiry, 28(4), 249-257. https://doi. org/10.1080/1047840X.2017.1373550

Burris, C. T., \& Jackson, L. M. (2000). Social identity and the true believer: Responses to threatened selfstereotypes among the intrinsically religious. British Journal of Social Psychology, 39(2), 257-278. https://doi.org/10.1348/014466600164462

Chapman, S., \& Schwartz, J. P. (2012). Rejecting the null: Research and social justice means asking different questions. Counseling and Values, 57, 24-30. https://doi.org/10.1002/j.2161-007X.2012. 00004.x

Crandall, C. S., \& Eshleman, A. (2003). A justification-suppression model of the expression and experience of prejudice. Psychological Bulletin, 129, 414-446

Eddy, S. R. (2004). What is Bayesian statistics? Nature biotechnology, 22(9), 1177-1178. https://doi.org/ 10.1038/nbt0904-1177

Fein, S., Hoshino-Browne, E., Davies, P. G., \& Spencer, S. J. (2003). The role of self-image maintenance in stereotype activation and application. In S. J. Spencer, S. Fein, M. P. Zanna, \& J. M. Olson (Eds.), Motivated social perception: The Ontario Symposium. (Vol. 9, pp. 21-44). Erlbaum.

Fiske, S. T. (2001). Effects of power on bias: Power explains and maintains individual, group, and societal disparities. In A. Y. Lee-Chai \& J. A. Bargh (Eds.), The use and abuse of power: Multiple perspectives on the causes of corruption. (pp. 181-193). Psychology Press.

Gelman, A., \& Shalizi, C. R. (2013). Philosophy and the practice of Bayesian statistics. British Journal of Mathematical and Statistical Psychology, 66, 8-38

Gonzalez-Voller, J., Crunk, E., Barden, S. M., Harris, S., \& Belser, C. T. (2020). A preliminary longitudinal study of multicultural competence in counselor education. Journal of Counseling \& Development, 98, 308-318. https://doi.org/10.1002/jcad.12325

Hall, D. L., Matz, D. C., \& Wood, W. (2010). Why don't we practice what we preach? A meta-analytic review of religious racism. Personality and Social Psychology Review, 14(1), 126-139. https://doi. org/10.1177/1088868309352179

Hays, D. G. (2020). Multicultural and social justice counseling competency research: Opportunities for innovation. Journal of Counseling \& Development, 98(3), 331-344. https://doi.org/10.1002/jcad. 12327

Helms, J. E. (2015). Taking action against racism in a post-racism era: The origins and almost demise of an idea. The Counseling Psychologist, 43, 138-145. https://doi.org/10.1177/0011000014564250

Hook, J. N., Farrell, J. E., Davis, D. E., DeBlaere, C., Van Tongeren, D. R., \& Utsey, S. O. (2016). Cultural humility and racial microaggressions in counseling. Journal of Counseling Psychology, 63(3), 269-277. https://doi.org/10.1037/cou0000114

Jackson, D. L., Gillaspy, J. A., Jr., \& Purc-Stephenson, R. (2009). Reporting practices in confirmatory factor analysis: An overview and some recommendations. Psychological Methods, 14(1), 6-23. https://doi.org/10.1037/a0014694

Jackson, R. D., \& Henderson, H. (2019). Criminal justice students' perceptions and awareness of racism and discrimination Race and Justice 1-24 https://doi.org/10.1177/2153368719873024

Judd, C. M., \& Park, B. (1993). Definition and assessment of accuracy in social stereotypes. Psychological Review, 100, 109-128

Khan, S. R., \& Lambert, A. J. (2001). Perceptions of rational discrimination: When do people attempt to justify race-based prejudice? Basic and Applied Social Psychology, 23, 42-54

Konrad, A. M. (2018). Denial of racism and the Trump presidency. Equality, Diversity, and Inclusion: An International Journal, 37(1), 14-30. https://doi.org/10.1108/EDI-07-2017-0155 
Kottler, J. A., \& Balkin, R. S. (2017). Relationships in counseling and the counselor's life. American Counseling Association.

Kozan, S., \& Blustein, D. L. (2018). Implementing social change: A qualitative analysis of counseling psychologists' engagement in advocacy. The Counseling Psychologist, 46, 154-189. https://doi.org/ $10.1177 / 0011000018756882$

Li, C. (2016). Confirmatory factor analysis with ordinal data: Comparing robust maximum likelihood and diagonally weighted least squares. Behavioral Research Methods, 48, 936-949. https://doi.org/10. 3758/s13428-015-0619-7

Litam, S. D. A. (2020). “Take your Kung Flu back to Wuhan”: Counseling Asians, Asian Americans, and Pacific Islanders with race-based trauma related to COVID-19. The Professional Counselor, 10(2), 144-156. https://doi.org/10.15241/sdal.10.2.144

Litam, S. D. A., Balkin, R. \& Hendricks, L. (in press). Assessing worry, racism, and belief in a just world. Journal of Counseling \& Development.

Litam, S. D. A., \& Oh, S. (In press). Effects of COVID-19 racial discrimination on depression and life satisfaction among young, middle, and older Chinese Americans. Adultspan Journal.

Litam, S. D. A., \& Oh, S. (2020). Effects of COVID-19 racial discrimination on Chinese Americans: Ethnic identity and coping strategy as moderators. Counseling Outcome Research and Evaluation. https://doi.org/10.1080/21501378.2020.1814138

Malkin, M. (2004). In defense of internment: The case for "racial profiling" in World War I. Regnery Publishing.

Morgan, G. S., Mullen, E., \& Skitka, L. J. (2010). When values and attributions collide: Liberals' and conservatives' values motivate attributions for alleged misdeeds. Personality and Social Psychology Bulletin, 36(9), 1241-1254. https://doi.org/10.1177/0146167210380605

Morrison, T. G., \& Kiss, M. (2017). Modern racism scale. In V. Ziegler-Hill \& T. K. Schackelford (eds.), Encyclopedia of personality and individual differences, (pp. 1-3). Springer International Publishing.

Oh, S., Litam, S. D. A., \& Chang, C. (In press). COVID-19 fueled subtle and blatant racism and stressrelated growth among international Asians in the United States: The roles of ethnic identity, resiliency, and coping. Asian American Journal of Psychology

Owen, J., Tao, K. W., Imel, Z. E., Wampold, B. E., \& Rodolfa, E. (2014). Addressing racial and ethnic microaggressions in therapy. Professional Psychology, Research and Practice, 45, 283-290. https:// doi.org/10.1037/a0037420

Owen, J. J., Tao, K., Leach, M. M., \& Rodolfa, E. (2011). Clients' perceptions of their psychotherapists' multicultural orientation. Psychotherapy: Theory. Research, \& Practice, 48, 274-282. https://doi. org/10.1037/a0022065

Pedersen, P. (1989). Developing multicultural ethical guidelines for psychology. International Journal of Psychology, 24, 643-652

Pedersen, P. B. (1988). A handbook for development multicultural awareness. American Association for Counseling and Development.

Pedersen, P. B. (1990). The constructs of complexity and balance in multicultural counseling theory and practice. Journal of Counseling \& Development, 68, 550-554

Ramirez Stege, A. M., Brockberg, D., \& Hoyt, W. T. (2017). Advocating for advocacy: An exploratory survey on student advocacy skills and training in counseling psychology. Training and Education in Educational Psychology, 11, 190-197. https://doi.org/10.1037/tep0000158

Ratts, M. J., Singh, A. A., Nassar-McMillan, S., Butler, S. K., \& McCullough, J. R. (2016). Multicultural and social justice counseling competencies: Guidelines for the counseling profession. Journal of Multicultural Counseling and Development, 44(1), 28-48. https://doi.org/10.1002/jmcd.12035

Roccas, S. (2005). Religion and value systems. Journal of Social Issues, 61, 747-759. https://doi.org/10. 1111/j.1540-4560.2005.00430.x

Sanchez, J. C. (2018). Trump, the KKK, and the versatility of White supremacy rhetoric. Journal of Contemporary Rhetoric, $8(1 / 2)$, 44-56

Savage, L. J. (1954). The foundations of statistics. Wiley.

Schreiber, J. B., Nora, A., Stage, F. K., Barlow, E. A., \& King, J. (2006). Reporting structural equation modeling and confirmatory factor analysis results: A review. The Journal of Educational Research, 99, 323-338. https://doi.org/10.1177/2158244016650240

Shin, R. Q., Smith, L. C., Welch, J. C., \& Ezeofor, I. (2016). Is Allison more likely than Lakisha to receive a callback from counseling professionals? A racism audit study. The Counseling Psychologist, 44, 1187-1211. https://doi.org/10.1177/0011000016668814 
Sidanius, J., \& Pratto, F. (1999). Social dominance: An intergroup theory of social hierarchy and oppression. Cambridge University Press.

Singh, G., \& Cowden, S. (2011). Multiculturalism's new fault lines: Religious fundamentalisms and public policy. Critical Social Policy, 31(3), 343-364. https://doi.org/10.1177/0261018311398782

Spangenberg, I. J. J. (2019). The religious roots of racism in the Western world: A brief historical overview. HTS Teologiese Studies/Theological Studies, 75(1). Online publication. https://doi.org/10. 4102/hts.v75i1.5187

Sullivan, A. C., Ong, A. C. H., La Macchia, S. T., \& Louis, W. R. (2016). The impact of unpunished hate crimes: when derogating the victim extends into derogating the group. Social Justice Research, 29(3), 310-330

Sue, D. W. (2005). Racism and the conspiracy of silence: Presidential address. The Counseling Psychologist, 33, 100-114. https://doi.org/10.1177/0011000004270686

Sue, D. W., \& Sue, D. (2016). Counseling the culturally diverse: Theory and practice (7th ed.). Wiley.

Swaine, J., Laughland, O., Lartey, J., \& McCarthy, C. (2015). Young black men killed by US police at highest rate in year of 1,134 deaths. The Guardian. Retrieved from https://www.theguardian.com/ us-news/2015/dec/31/the-counted-police-killings-2015-young-black-men

Tarman, C., \& Sears, D. O. (2005). The conceptualization and measurement of symbolic racism. Journal of Politics, 67(3), 731-761. https://doi.org/10.1111/j.1468-2508.2005.00337.x

Uhlmann, E. L., \& Brescoll, V. L. (2011). Bayesian racism: A modern expression of contemporary prejudice. In Simon, E. L. (eds), Psychology of stereotypes (pp. 137-148). Nova Science Publishers, Inc.

Uhhmann, E. L., Brescoll, V. L., \& Machery, E. (2010). The motives underlying stereotype-based discrimination against members of stigmatized groups. Social Justice Research, 23, 1-16. https://doi. org/10.1007/s11211-010-0110-7

Publisher's Note Springer Nature remains neutral with regard to jurisdictional claims in published maps and institutional affiliations. 